\title{
Influencias del Romanticismo Europeo, en "Ana Bolena", de Fernando Calderón
}

\author{
INTRODUCCION
}

$\mathrm{A}^{\mathrm{N}}$ $\mathrm{N}$ las historias generales de la literatura mexicana se considera

a Fernando Calderón y Beltrán como uno de los autores románticos mexicanos de importancia. También se nos dice que influía en los poetas románticos mexicanos la literatura europea de la época. Pero cuando se mencionan influencias concretas, se nombra a ciertos autores, unos con razón $\mathrm{y}$ otros sin ella, $\mathrm{y}$ muchas veces se ignora, sin razón, a otros.

Este estudio tiene como fin definir un poco más los orígenes del romanticismo mexicano reflejado en la Ana Bolena de Fernando Calderón y Beltrán. Ya que de esta obra se da sólo lo que hemos podido cotejar directamente con obras de otros autores, ofrecemos a continuación una reseña general, para que mejor se entienda el trabajo. Lo que no damos de esta obra o lo consideramos característico del romanticismo en general (véase la conclusión), o hasta ahora lo estimamos original porque no hemos encontrado semejanzas. No hay, pues, en este trabajo la pretensión de agotar el tema.

\section{ANA BOLENA}

Smeton, cortesano de la reina, Ana Bolena, está perdidamente enamorado de ella; comprendiendo que su amor es imposible, lo declara sólo en trovas, cuando la reina le manda que le disipe la melancolía que siente. El rey, Enrique VIII, empieza a interesarse por Juana Seymour, dama de la corte. Cromwell, primer ministro, 
movido por la venganza (la reina lo ha insultado públicamente en una ocasión), incita la pasión incipiente del rey, y busca un pretexto para que Juana suplante a Ana. Tal pretexto lo halla una vez que Smeton besa, inadvertidamente, un retrato de la reina que lleva consigo; retrato que Smeton ha hecho, sin saberlo la reina. Se la juzga infiel y se la lleva al cadalso, triunfando asi el acentuado sentimiento de venganza de Cromwell.

Las referencias bibliográficas, corresponden a cada número.

En la escena primera del drama se sabe, por la conversación de dos grupos de jugadores, que (1) Smeton, cortesano alli presente, se ha enamorado perdidamente de la reina; (2) que el rey se está interesando mucho por Juana Seymour, dama de la reina, y (3) que Cromwell, ministro del rey, parece estar aún más interesado que el rey mismo, en que éste enamore a Juana porque quiere vengarse de cierto ultraje que Ana Bolena le hizo en público una ocasión.

El primer acto se titula "El baile": "Gran salón en el palacio de White-Hall,..." La decoración de la primera escena de Catherine Howard es parecida: "La salle de réception au palais White-Hall." 1

En muchos dramas románticos se encuentra expuesto el hilo de la trama por medio de una conversación entre criados o entre personajes de menor importancia: en Don Alvaro o en El Trovador, por ejemplo. Pero recuerda más el comienzo de Ana Bolena la escena 10 del primer acto de $U n$ desafio de Larra; ${ }^{2}$ no sólo porque en este drama se descubra ambiente parecido - los cortesanos hablan de todo lo que pasa en la corte-, sino también por las semejanzas que siguen: Cuando insinúan los cortesanos que Smeton, en Ana Bolena, está enamorado de la reina, éstos se ríen y dicen:-Bien dicho. En Un desafio los cortesanos rien maliciosamente de las murmuraciones. En Ana Bolena se ofende Smeton, después del "Bien dicho" citado. En $U n$ desafío Sidney, ofendido, pone fin a las murmuraciones y sale en defensa de la reputación indignamente calumniada. En Ana Bolena el cortesano tercero ruega a los demás que guarden secreto todo lo que él les ha dicho porque si no, corre peligro. En $U n$

13.

$28 \mathrm{~b}$ 
desafio Overbury, antes de expresar sus calumnias, les ruega a los circunstantes que le prometan guardar secreto todo lo que él les diga. (También en El trovador hay quien quiere que se guarde el secreto.)

En cuanto al elemento de venganza mencionado al principio de este estudio, en La cisma de Ingalaterra, jornada $x$, escena $8,{ }^{3}$ el rey se está enamorando de Ana Bolena; y Volseo, favorito del rey, incita ese amor porque quiere vengarse de la reina, quien lo ha llamado: "loco, necio, vano; hijo de carnicero..."

La segunda escena se compone de un soliloquio melancólico y fatalista en que Smeton confiesa que sí ama él, pobre cortesano, a Ia reina. El fatalismo, causado por el amor contrariado, es muy común en las obras románticas. Esta escena recuerda, sin embargo, la sexta del segundo acto de $E l$ paje, ${ }^{4}$ en que el paje habla del amor inalcanzable que siente por su señora, doña Blanca.

Al fin de este soliloquio melancólico, saca Smeton un retrato de Ana Bolena que lleva oculto en el pecho, pendiente de una cadena de oro, y lo mira. En Un desafío citado arriba, acto Ir escena 1, saca Sidney una caja del pecho, y besa repetidas veces lo que contiene. En el acto II, escena 12, se nos dice que lo que lleva en la caja es el retrato de la duquesa, su "objeto sacrosanto". En Marion de Lorme, $\mathrm{v}, 3,5$ Didier, preso, saca el retrato que lleva de Marion, lo mira y habla de manera muy desesperada, como Smeton. En Catherine Hoz'ard, cuadro II, escena 3, ${ }^{\circ}$ Ethlwood habla de "portrait ... pendu a ce collier..." Por supuesto, no son estos los únicos ejemplos semejantes encontrados en la literatura: se encuentran muchos más en los dramas del siglo de oro español, en Bretón de los Herreros, en Lamartine: Souvenir: ${ }^{7}$

Mais ta jeune et brillante image, que le regret vient embellir, dans mon sein ne saurait vieillir.

Cromwell ha visto que Smeton, inadvertido, ha sacado el retrato de Ana y lo ha besado. Con esto cree tener prueba suficiente para

32.

45.

$56 \mathrm{~b}$.

63.

77 .' 
acusar a Ana de infidelidad y para llevarla al patíbulo. Esto recuerda la escena 15, jornada III, de La cisma; como sospecha que Anà es infiel, se oculta el rey y ve que Carlos, a quien Ana ha despreciado por casarse con el rey, devuelve a ésta sus cartas. Sale el rey y se sorprende al ver que en una de las cartas que ha dejado caer Ana decía ella a Carlos: "Vos sois, Carlos, mi dueño". ${ }^{8}$ Con esto basta para que aprehendan a Ana y la hallen culpable.

En la quinta escena dice Enrique:

Enrique Percy,

el conde de Northumberland, amaba

a Ana Bolena, y pienso que contrajo

esponsales con ella, antes que al trono

fuese llamada: si esto fuese cierto

mi matrimonio es nulo.

En La cisma de Ingalaterra: Ir, 15, dice el rey que Catalina

Fué de mi hermano mujer:

y así conmigo no pudo

ser válido el matrimonio ${ }^{9}$

En la séptima escena llega Enrique Percy a avisar al rey que Catalina, "la augusta desterrada", ha muerto. En La cisma de Ingalaterra, IIr, 21, es la Infanta quien trae la noticia de la muerte de Catalina.

En la escena Ix el rey, está melancólico porque piensa en Juana Seymour. Entra Ana, quien viéndolo serio, dice:

\author{
Señor, ¿vos tan retirado? \\ ¿vos tan triste? \\ Enrique (Con sequedad): Si, no tengo. \\ motivos para alegrarme.
}

En La cisma de Ingalaterra, II, 2, el rey confiesa a Volseo que está apasionado de Ana Bolena y que por eso está pensativo. En Ir, 3, viéndole la reina así, dice:

8. 2.

92. 


¡Vos sin salud, señor mío,
y yo viva...! i Vos con causa
de tristeza, y yo no muero!
Poco siente quien os ama.
Rey iQué prolija!
Reina Estáis mejor?
Rey iQué cansada...!10

ACto II. escena I. Ana Bolena y su hermano Rochford.

Le refiere Ana un sueño espantoso que ha tenido. La cisma empieza con la descripción de un sueño del rey. Los dos son parecidos; pero no en el contenido, sino en el uso que de ellos se hace en el drama. Los dos sirven de presagio para los sucesos principales que siguen en cada drama. En Ana Bolena ve anticipadamente su muerte Ana, con el sueño. En La cisma sueña el rey que se le aparece una mujer hermosísima. Se queda confuso. Más se confunde, cuando después se le presenta a Ana y se da cuenta de que esta Ana no es sino la hermosísima figura con que ha soñado. Termina por casarse con ella, abandonando a Catakina de Aragón.

Al fin de esta primera escena, dice Ana que se ha educado en Francia. En $L a$ cisma, I, 4, se nos dice que Ana ha vivido en Francia porque su padre fué embajador inglés en la corte francesa.

En la segunda escena, entera Juana Seymour a Ana de que el rey la pretende. Responde Ana, en parte, refiriéndose a Cromwell, a quien culpa:

¡Miserable!

$¿$ Posible es tanta bajeza?

¡Pero al rey le pasará este' capricho y caerá ante mis pies tu cabeza!

Tú volverás a la nada.

Cromwell infame y traidor:

¡Tú temblarás al furor

de una mujer ultrajada!

En La cisma, IIr, 4, Ana es de carácter parecido:

Muera Volseo. ¿Tirana

me llaman? ¿Ingrata soy?...

10. 2 . 
Firme en mi venganza estoy, derriben mis manos hoy a quien me levantó ayer. 11

ACTO III. ESCENA I. Dice Cromwell que el rey escribe y que acaso está refutando "aquel librote de los Siete Sacramentos que escribió él mismo". En La cisma, I, 1, el rey le dice a Volseo que está escribiendo en defensa de los Siete Sacramentos.

Después lee Cromwell los nombres de los que han de juzgar a Ana. Entre ellos se encuentra un tio de Ana, quien

$$
\begin{aligned}
& \text { Está irritado, y supone } \\
& \text { que el crimen es cierto. }
\end{aligned}
$$

En La cisma, IIt, 18, el juez, "irritado" pariente de Ana, es su padre mismo.

esCENA Ir. Se jacta Cromwell de que se aproxima ya su venganza;

Vuela, navecilla mia, con viento en popa...

que recuerda la Canción del pirata de Espronceda:

Con diez cañones por banda, viento en popa, a toda vela, no corta el mar sino vuela un velero bergantín...12.

ESCENA VIr. Soliloquio de Enrique vIrI:

¿Qué clase de sentimiento turba mi serenidad?

¿Es el amor? ¿la piedad?

[Acaso el remordimiento!

¿Puedes juzgar con razón

que Ana Bolena es perjura,

Enrique? ¿Quién to asegura?

112.

124. 
Lo cual recuerda La cisma, Ir, $12:^{13}$

Confieso que estoy loco y estoy ciego, pues la verdad que adoro, es la que niego.

Pero si un hombre el daño no alcanzara, aunque errara, parece que no errara; que en $\tan$ confusa guerra, sólo errara el que sabe cuándo yerra.

Bien sé que me ha engañado

Volseo; $y$ he quedado

de su falso argumento satisfecho; ...

escena $x$. Se queja.Percy de que se le haya nombrado juez, a él que amaba a Ana antes de que ella se casara con el rey, sólo porque creen que ahora quiere vengarse de ella. Ruega que se registren los anales de su familia, y se verá que en muchas generaciones no se encuentra un ejemplo de bajeza. Esto último recuerda Hernani, III, $6,{ }^{14}$ cuando Ruy Gómez, en vez de entregar a Hernani, responde refiriendo las hazañas $y$ honores recibidos de cada uno de sus antecesores. Acepta Percy, al fin, el nombramiento de juez; pero sólo por ver qué puede hacer por salvar a Ana. En María Estuarda de Bretón de los Herreros, II, 3, ${ }^{15}$ Mortimer vuelve a la corte después de varios años de ausencia, como Percy en Ana Bolena, y trata de salvar a María.

Acto Iv, 2: Cromwell y Percy.

Percy - Os buscaba.

que recuerda Bedford en Un desafio, 1,11 :

- Por fin os encuentro. 16

Percy ... Cromwell, tomad el partido

de la reina...

Ya conocéis mi opulència:

vuestra será desde hoy,

si defendéis la inocencia.

132.

146.

151.

$168 \mathrm{~b}$. 
Ahora véase lo que dice Dermod en Robert Dillon, III, $1:^{1 \mathbf{7}}$

... Yo comprometo todos mis bienes, yo os entrego cuanto poseo... (B) Venid a retractar vuestra culpable declaración; (A) detened a la muerte que va a segar ya a un anciano y la sangre del inocente $(C)$ no recaerá sobre vuestra cabeza...

Cuando Cromwell responde que no, dice Percy, entre otras cosas:

$$
\begin{aligned}
& \text { ¡Tiembla! Ya la eternidad } \\
& \text { se está abriendo para ti. } \\
& \text { La sangre que se derrama } \\
& \text { por tu culpa, se alzará } \\
& \text { y tus huesos quemará, } \\
& \text { como abrasadora llama: } \\
& \text { la cólera del Eterno } \\
& \text { caerá sobre ti, malvado, } \\
& \text { te recibirá el infierno... }
\end{aligned}
$$

Eduardo, en Robert Dillon, de Larra, dice:

iAh! Si vuestro perjurio (hay perjurio en Ana Bolena también) no ha provocado contra vuestra cabeza mil brazos vengadores, si la tierra asombrada de soportar vuestro infando peso no ha temblado (A) ni ha entreabierto sus profundos abismos debajo de vuestros pies... (B) No acuso más que a ti. (C) y te acuso delante de Dios! (D) Puesto que... obcecado por tu infernal rencor (F) ... el abismo... no volverá a cerrarse sino después de haberte tragado a ti también, anda desdichado (E). ${ }^{18}$

escena 3. Percy, defendiendo a Ana, dice en el Parlamento: (A)

Aquel que tenga una alma tan mezquina, que la verdad sagrada conociendo tema irritar al rey, y la justicia tuerza tal vez por $\tan$ innoble miedo, deje la vestidura respetable, y desocupe el elevado asiento, que yo no temo al rey ni a sus ministros.

Esto recuerda la escena 1, cuadro vir, de Catherine Howard, cuando Sussex, el único que defiende a Ana, dice:

178 a.

188 a. 
... Le parliment (A) est une cour d'indépendance et de justice, qui ne doit compte de ses arrêts qu'a Dieu seul. (B) ... Comme ce resultat sera un jugement mortel (lo que fué en Ana Bolena), et ce jugement un remords ou une honte pour toute la Chambre qui l'aura porté, je dépose a la place (D) où, depuis . siècles siègent mes aïeux le manteau (C) de pair...19

QUINTo ACTO. ESCENA 4, cuadro primero. Se ha sentenciado a Ana. Soliloquio de ésta:

Corre el tiempo presuroso, la noche se acerca ya.

¿Qué pensamiento espantoso!

Ya tu luz ioh sol hermoso!

para mí no brillará.

Si, brillará todavía,

pero por última vez, en la hora de la agonía, en que vuele el alma mía ante su terrible Jues... i Morir tan joven, morir!

que recuerda al soliloquio de Catherine, en Catherine Howard, acto $\mathrm{v}$, cuadro viri, escena 2, después de que ella sabe que la han sentenciado a muerte:

Une heure encore et puis plus rien; (A) et, demain, le jour se levera sur mon tombeau! (B) ... moi si jeune, (D) ... et n'avoir plus qu'a étendre le bras pour toucher l'eternité!... (C) 20

Acto v. Cuadro II, escena 1. Cromwell:

Ya está toro

para el suplicio dispuesto.

Hice venir al verdugo

de Calé, que es el más diestro, por que la pobre señora tenga que padecer menos.

Catherine Howard, Acto v, cuadro vII, escena 3. Hablan de Anne Boleyn: 

William
D'un seul coup?...
Jackson D'un seul, vlan! Oh, le roi avait choiri un homme fort habile, l'exécuteur.
de Calais, qu'il avait fait venir exprès. 21

En la tercera escena de este último cuadro, Sir William' trata de convencer al rey de que Ana es inocente, diciéndole que ha oído las palabras que pronuncia cuando se halla sin testigos, y que en sus delirios no se le ha escapado una palabra que iridique delito alguno. En Catherine Hozvard, acto rv, cuadro vr, escena I, Catherine en "son sommeil trahit je ne sais quelle craint ou quel remords", y es que sigue ella pensando en su antiguo amante Ethelwood.

\section{I}

En el estudio de fuentes de Ana Bolena, no debe olvidarse el Enrique VIII, de Shakespeare, que hasta ahora no se ha mencionado. En esta obra se encuentran semejanzas en los incidentes, que no se han expresado o de los cuales se ha hecho poco caso. Leyendo esta obra, se entienden mejor las intrigas del Cromwell de Ana Bole$n a$, como se entienden también, por el colorido semejante, las escenas en que se acusa y se defiende a Ana Bolena. Las acusaciones contra Buckingham (en el Enrique VIII), si no son ficticias, si son insuficientes para sentenciarlo. Los acusadores no son más que secuaces o sobornados del ministro. Buckingham hace todo lo que puede por defenderse, pero su esfuerzo es inútil. Algo semejante ocurre en Ana Bolena, en lo que se refiere a Ana. La reina Catalina defiende a Buckingham $(I, 2)$. El que aboga por Ana Bolena es el duque de Northumberland.

En IV, 3, dice Cromwell que es muy doloroso que él sea el acusador. En el Enrique VIII, II, 4, no quiere la reina Catalina que sea Wolsey uno de los jueces, porque cree, "Induced by potent circumstances, that you are mine enemy", o sea que Wolsey mismo es el acusador.

En el Enrique VIII, II, 2, el rey está "full of thoughts and troubles" porque "his conscience has crept too near another lady" (Anne Bullen: Ana Bolena), no porque le atormenta, después de veinte años 
de casado con Catalina de Aragón, haberse casado con ella, su cuñada. En Ana Bolena, I, 8, está el rey tan alejado (en Eurique VIII, II, 2: "I left him private") y tan triste, no porque se le haya anunciado la muerte de Catalina, sino porque Juana Seymour lo "arrastra" con sta "impulso secreto, sobrehumano", I, 5.

En La cisma, ya citada, está Catalina (III, 1) "en un pobre castillo junto a Londres, padeciendo mil desdichas"; en Enrique VIII, Iv, 1, en Ampthill; en Ana Bolena "gime en el retiro de.Haptill", I, 1.

Como ya se ha visto, Ana Bolena, empieza con un baile en White Hall. En Enrique VIII hay recepción y baile de máscaras en York Place, I, 4, que después, IV, 1, llaman Whitehall.

En los dos dramas hay un Enrique VIII, una Catalina, un Cromwell, una Ana Bolena, un duque de Norfolk, un Rochford, conde o duque de, Northumberland:

Dicen de la pobre Catalina, II, 2, que ella "loves him (Enrique VIII) with that excellence that angels love good men". En Ana Bolena Enrique dice a Juana Seymour: “ Te amo, como ama el ángel a Dios!', III, 8.

Catalina dice, cuando la acusan: "Heaven is above all yet; there sits a judge that no king can corrupt." Ana Bolena dice, Iv, 4: "Milores, hay otro Juez, / que es superior a vosotros".

Con estos ejemplos esperamos haber demostrado que debe considerarse el Enrique VIII, junto con La cisma de Ingalaterra, de Calderón de la Barca, y con los dramas románticos ya mencionados del siglo xIx, como una de las fuentes de Ana Bolena de Calderón y Beltrán, romántico mexicano.

\section{CONCLUSION}

Se ha dicho, en la Introducción de este estudio, que al escribir Calderón y Beltrán su Ana Bolena, se inspiró en autores europeos, sobre todo los románticos franceses y españoles. De acuerdo con el estudio hecho podremos formular la conclusión siguiente: para la trama en general y para ciertos incidentes adicionales, se sirvió nuestro autor de La cisma de Ingalaterra, de Calderón de la Barca; drama que trata de la caida de Catalina de Aragón y del ascenso de Ana Bolena. También creemos que conocia el drama de Dumas que trata de la caída de la quinta mujer de Enrique VIII, Catherine Howard, 
y que se atuvo a este drama, para ciertos incidentes, Se ven también ciertos vestigios de los dramas de García Gutiérrez. Más parecido se encuentra, sin embargo, con los dramas de Larra; sobre todo, con Un desafío y con Robert Dillon. También se ve que conocía el autor las obras de Bretón de los Herreros. De Víctor Hugo se percibe uno que otro tecuerdo.

Además de las fuentes más o menos concretas ya citadas, hay que mencionar ciertos caracteres temáticos del romanticismo que se encuentran en Ana Bolena, los cuales no hemos mencionado hasta ahora; pero no porque no creamos que contribuyan de modo importante a hacer más romántica la obra que hemos estudiado, sino porque creemos que estos caracteres merecen estudio por separado. Además, no era nuestra intención adscribir fuentes concretas en este estudio, a aspectos tan comunes como el fatalismo, el tema sepulcral, el mal del siglo, lo pasional, lo. medieval...

$$
\begin{gathered}
\text { Pablo Avila, } \\
\text { University of California, } \\
\text { Santa Bárbara, California. }
\end{gathered}
$$

\section{BIBLIOGRAFIA DE OBRAS CITADAS}

1 Obras de Bretón de los Herreros. Madrid. Imprenta de Miguel Ginestra, 1883.-Maria Estuarda, en vol. 1.

2 Biblioteca de Autores Españoles. Tomo xIr. Comedias de don Pedro Calderón de la Barca, Madrid, 1849.-La cisma de Ingalaterra.

3 Théatre Complet de Alexandre Dumas. Michel Levy Fréres.'Paris.Catherine Howard, en vol. mr.

4 José de Espronceda. Obras poéticas. Casa editorial Maucci. Barcelona, s. $f$.

5 Obras escogidas de Antonio García Gutiérrez. Edición hecha en obsequio del autor. Madrid, 1866. Imprenta y estereotipía de M. Rivadeneyra.-El paje.

6 Oeturres Completes. Víctor Hugo. J. Hetzel. Paris n. d.-Hernani (a); (b) Marion de Lorme.

7. Alphonse de Lamartine. Premières Méditations Poétiques. La mort de Socrate. Paris. Furne et Cie. Pagnerre. L. Hachette et Cie. Editeurs, 1860.

8 Mariano J. de Larra. Obras complefas de Fígaro. Quinta edición. París, 1883. Bautry. Librería Europea. Dos tomos.-(a) Roberto Dillon. (b) Un desafio. 